\title{
Antitumor properties of histamine in vivo
}

\section{To the Editor:}

Yang et al. ${ }^{1}$ recently reported that mice with histamine deficiency due to genetic disruption of histidine decarboxylase (HDC) show impaired myeloid cell differentiation. The absence of histamine formation caused accumulation of immature myeloid cells (IMCs), which was accompanied by an increased susceptibility to chemically induced cancer ${ }^{1}$. Exogenous histamine reversed the accumulation of tumor-promoting IMCs in $\mathrm{Hdc}^{-/-}$ mice, suggesting a potential benefit of histamine-based therapy in cancers $^{1}$, where IMCs are believed to contribute to an unfavorable course of disease ${ }^{2}$. Given the effect of exogenous histamine on IMCs, we were surprised that the authors did not discuss the in vivo effects of histamine on cancer development in animals. As seen in Table 1, histamine is an antitumor agent in several histiotypes of experimental cancer $^{3-7}$.

The authors also did not mention that histamine has been evaluated in clinical trials in cancer as an inhibitor of immunosuppressive myeloid cells $^{8}$. In metastatic renal cell carcinoma, the addition of histamine to interleukin-2 immunotherapy was reported to reduce the number of intratumoral macrophages ${ }^{9}$, implying an effect on the myeloid compartment resembling the results obtained by Yang et al. ${ }^{1}$. Furthermore, histamine is approved for use in 31 European countries and Israel to prevent relapse in acute myeloid leukemia (AML), a disease characterized by the accumulation of immature myeloid cells. The therapeutic use of histamine in AML aims to reduce myeloid cell-induced immu- nosuppression of cytotoxic lymphocytes ${ }^{8,10}$. In light of these previous findings, and considering the results presented by Yang et al. ${ }^{1}$, further studies to define mechanisms of relevance to the antitumor properties of histamine in vivo seem highly warranted.

\section{Fredrik B Thoren ${ }^{1,2}$, Johan Aurelius ${ }^{2}$ \& Anna Martner ${ }^{2}$ \\ ${ }^{1}$ Department of Hematology, Sahlgrenska Academy at University of Gothenburg, Gothenburg, Sweden. ${ }^{2}$ Cancer Centre Sahlgrenska, University of Gothenburg, Gothenburg, Sweden. \\ e-mail: fredrik.thoren@gu.se}

\section{COMPETING FINANCIAL INTERESTS}

The authors declare no competing financial interests.

1. Yang, X.D. et al. Nat. Med. 17, 87-95 (2011).

2. Gabrilovich, D.I. \& Nagaraj, S. Nat. Rev. Immunol. 9, 162-174 (2009).

3. Burtin, C., Scheinmann, P., Salomon, J.C., Lespinats, G. \& Canu, P. Br. J. Cancer 45 , 54-60 (1982).

4. della Rovere, F., Broccio, G., Granata, A. \& Fimiani, V. Oncol. Rep. 1, 175-177 (1994).

5. Suonio, E., Tuomisto, L. \& Alhava, E. Agents Actions $41 \mathrm{Spec}$ No, C118-C120 (1994).

6. Tatsuta, M. et al. J. Natl. Cancer Inst. 76, 277-281 (1986).

7. Hellstrand, K. Semin. Oncol. 29, 35-40 (2002).

8. Martner, A. et al. Expert Rev. Hematol. 3, 381-391 (2010).

9. Donskov, F., Hokland, M., Marcussen, N., Torp Madsen, H.H. \& von der Maase, H. Br. J. Cancer 94, 218-226 (2006).

10. Brune, M. et al. Blood 108, 88-96 (2006).

Table 1 Histamine in experimental cancer

\begin{tabular}{lll}
\hline Research group & Histiotype & Effect of histamine \\
\hline Burtin et al. & Fibrosarcoma & Inhibition of tumor growth and prolonged survival in mice \\
Tatsuta et al. & Intestinal adenocarcinoma & Reduced incidence of chemically induced tumors in the small intestine in rats \\
Hellstrand et al. (reviewed in ref. 7) & Melanoma & Prevention of melanoma metastasis formation in mice \\
Suonio et al. & Colorectal carcinoma & Reduction of tumor size of transplanted human colon carcinoma cell in mice \\
della Rovere et al. ${ }^{4}$ & Ascitic sarcoma & Protection of $80 \%$ of mice from a lethal inoculum of sarcoma cells \\
Asea et al. (reviewed in ref. 7) & Lymphoma & Enhanced clearance of YAC-1 lymphoma cells in mice
\end{tabular}

\section{Yang and Wang reply:}

We would like to thank Thoren et al. ${ }^{1}$ for their comments on our recent study ${ }^{2}$ and for highlighting important previous preclinical and clinical studies on the effects of histamine in cancer. Indeed, we did not have the space to cite the many excellent prior research efforts that have employed histamine or histamine receptor antagonists as antitumor agents. We are grateful to Thoren et al. ${ }^{1}$ in particular for calling to our attention the fact that histamine has been approved in Europe and Israel for treatment of $\mathrm{AML}^{3,4}$. Nevertheless, the effects of histamine in cancer models are often paradoxical, and the mechanisms for the antitumor effects of histamine have in the past been unclear. Histamine has multiple physiological roles and targets; we are aware of other earlier literature that suggested direct effects of histamine on cancer cell growth, and a number of preclinical studies have shown antitumor effects of $\mathrm{H}_{2}$ receptor antagonists ${ }^{5,6}$. In addition, whereas Martner et al. ${ }^{7}$ suggested that histamine is an inhibi- tor of immunosuppressive myeloid cells, our studies in mice indicate that the effect is primarily on both CD $11 b^{+} \mathrm{Ly}_{6 \mathrm{G}^{+}}$and $\mathrm{CD} 11 \mathrm{~b}^{+} \mathrm{Ly} 6 \mathrm{C}^{+}$ immature myeloid cells (IMCs), and the latter are suggested to be the major suppressor population ${ }^{2,8}$. Nevertheless, work from us and them is consistent with the conclusion that histamine seems to reduce the mobilization and circulating numbers of myeloid cells and inhibit progression of some types of cancer ${ }^{9}$. We agree that further studies are needed to define the effects of histamine in the regulation of myeloid differentiation and maturation, which seems to be central to the promotion of cancer.

\section{Xiang Dong Yang \& Timothy C Wang}

Division of Digestive and Liver Diseases, Department of Medicine and Irving Cancer Center, Columbia University, New York, New York, USA. e-mail:tcw21@columbia.edu 